\title{
Mentes educadas ¿Cómo las herramientas cognitivas dan forma a nuestro entendimiento?
}

\section{Kieran Egan}

Santiago de Chile: Editorial Universidad Finis Terrae, 2018. 421 páginas.

El libro Mentes educadas del teórico de la educación Kieran Egan, recientemente traducido y lanzado por la Colección de Educación de la Universidad Finis Terrae, es una referencia fundamental para cualquier persona interesada en educación. Se trata de una visión completa que explica el problema del concepto educativo desde sus orígenes con una genialidad magistral. El profesor Egan inserta las visiones sobre la educación en un contexto histórico y de pensamiento que permite comprender los procesos de un modo ejemplar. No se trata de otro libro sobre cómo educar, sino que va al fondo del tema del cómo y por qué surge la educación y por qué hay cosas que interesan y otras que no. Parte de una base filosófica fundamental, explicando la intrínseca unión entre percepción, pensamiento y sentimiento. Lo que él llama perfinkers (perception, feeling and thinking) sabe que es una unidad inseparable y esto debe estar en la médula y corazón de la educación. Para enseñar y aprender necesitamos comprometer las emocione; si no es así, lo que enseñemos se va a olvidar. Con esta idea central desarrolla un recorrido teórico con aplicaciones prácticas en este libro, la llamada biblia de la educación imaginativa.

La educación imaginativa, entonces, propone poner como foco las emociones. Hay que comprender que nosotros percibimos, entendemos y sentimos al mismo tiempo. Que lo que se conoce no es neutro, produce emociones. Por lo mismo, a la hora de enseñar debemos procurar enganchar las emociones, comprometer la imaginación de aquellos a los que se les enseña; de lo contrario, lo que se enseñe se va a olvidar. No queremos que nuestros niños vayan al colegio por catorce años y que luego olviden todo o gran parte de lo que se supone que aprendieron, porque en realidad no aprendieron, sino solo estudiaron para la prueba y luego de ésta lo olvidaron. Si vamos a estudiar para olvidar, ¿qué sentido tiene ir al colegio? Buscamos aprendizajes duraderos, para eso la única forma es comprometer las emociones. Es el sentir el que permite recordar. De hecho, la palabra recordar viene de "corazón" (cuore-re-cordare) y significa "volver a sentir".

Los colegios, como los entendemos hoy, son una invención del siglo XIX que pretenden responder a una sociedad industrial y que quieren formar 
personas para servir a esa realidad industrial. La idea era formar operarios, personas útiles al sistema, pero no pensantes. La idea de educación para todos, de someter a todos los niños a un proceso industrial, con un input, proceso y output que espera resultados similares en los niños tras el proceso, es algo nuevo. Pero para muchos educadores parece haber estado siempre. Es algo nuevo y como modelo, perfectible y, sí, cambiable. Los ciento cincuenta años de la implementación de las leyes de Instrucción Primaria en el mundo han podido mostrar los beneficios y debilidades del sistema y hoy es un buen momento para cuestionar lo que no es lógico y lo que no está bien. No se trata de destruir la idea de instrucción para todos, sino de mejorarla. Reconocer algo esencial, los niños no son iguales, ni serán iguales. No educamos clones y, por lo tanto, aunque apliquemos el mismo proceso, los resultados no serán iguales. $Y$ teniendo en cuenta que en todas partes del mundo la noción de que el sistema está en crisis es real y absoluto, este libro se hace esencial, ya que entiende y explica el problema y propone, como pocos, soluciones reales y factibles a este dilema de tres caras: trilema.

Como nuestro sistema fue creado durante la Era Industrial y nacerá con una contradicción intrínseca, que es hasta hoy el origen del gran problema de la educación, a los colegios se les pide tres cosas que son incompatibles entre ellas, lo que hace imposible poder cumplir con lo que se les pide de un modo completo. Las tres cosas son imposibles de realizar al mismo tiempo y cada establecimiento ajusta lo mejor que se puede a este trilema y flota del mejor modo que cree. El profesor Egan explica magistralmente que desde sus orígenes se les pide a los colegios que preparen a los niños para encajar en la sociedad establecida, lo que se conoce como "socialización". Se busca preparar a los niños para ser parte activa de la sociedad, buenos ciudadanos, obedientes y que asientan con las reglas imperantes. Es una idea que aparece a fines del siglo XIX cuando Emil Durkheim, sociólogo francés, ve el poder socializador del aula. Desde entonces se ha usado la educación para este fin, con mayor o menor énfasis, pero siempre se ha usado. El Estado entiende que el aula y el proceso educativo es un buen momento para permear las cabezas de los educandos en su favor. De hecho, los totalitarismos rápidamente se hicieron de la educación para desde ella formar a los niños en la ideología. Ya Lenin decía, "denme a un niño de tres años y haré de él un ferviente bolchevique". Luego Mussolini y Hitler harían lo suyo (de hecho, son más parecidos de lo que la gente cree). La idea de Durkheim está muy presente y explica la obsesión de los gobiernos, incluso hoy, lejana la época de los totalitarismos, a tener currículo únicos y a manipular contenidos en su favor. No es la socialización lo que se cuestiona, sino que cuánto socializar.

Lo segundo que se pide a los colegios es que conecten a los niños con todas esas verdades que debieran ser sabidas. Es la idea que hay verdades que merecen ser conocidas, es la obsesión del llamado "academicismo", aquello que 
todo hombre debe saber. Esa idea, dice Egan, viene de Platón, filósofo griego que creía que la verdad existía y se podía alcanzar. La verdadera realidad era el llamado "mundo de las ideas", en que habitaba el ser de las cosas y lugar donde alguna vez estuvimos para luego caer en este mundo, que no es más que las sombras de la verdadera realidad. Para Platón, el conocer es recordar lo que alguna vez conocimos, por eso su teoría del conocimiento es la llamada "reminiscencia", que es recordar. Es Platón el que en su Academia establece las cosas que una persona debe saber, de hecho, para él lograr una persona educada implica al menos cincuenta años de estudio, que dista bastante de nuestro sistema que establece catorce. Es esta idea platónica la que dicta que hay que conocer los llamados clásicos y el saber acumulado en nuestra cultura. Esta es la idea que se centra en los contenidos. Esta es la línea que toman los llamados tradicionalistas en la educación. Más contenidos y mediciones de contenidos mismos. El gran problema de esta visión en relación a la anterior es que ya vemos un problema, porque si yo quiero que acepten las reglas, debo evitar ciertos contenidos, ya que de lo contrario van a disentir. El amplio academicismo que enseña profundos contenidos humanistas genera personas críticas que cuestionan el sistema y que muchas veces van en contra de él. Por lo tanto, ya para aplicar lo que se les pide como uno y dos estamos en un problema, pues ¿cómo socializo formando una idea establecida si al conectarlo con los saberes que deben conocer disentirán? Es el gran problema de los Estados para con los humanistas. Lo peor es que lo tercero que se les pide es incompatible con los dos anteriores.

Lo tercero que se pide a los colegios, según Egan, es que saquen del interior del niño ese potencial que está en su interior, dejándolo libre para encontrar lo que está en ellos y desarrollarlo. Dejar al niño libre para que florezca. Esta idea viene de Jean Jacques Rousseau, filósofo ilustrado suizo que vive en Francia durante la llamada "llustración". Es el gran pensador político que inspira la Revolución Francesa. Este autor, además de escribir su famoso Contrato Social, escribe un libro llamado El Emilio, en el que llama a los tutores a dejar al niño libre para que logre sacar desde su interior ese conocimiento que ya está en él. El conocimiento vendrá solo en la medida en que el niño crezca. El niño debe ser guiado por el tutor y dejado libre, ya que el niño es bueno y la sociedad lo corrompe. No es lejano el Rousseau político del educacional. Esta es la idea de los llamados "progresistas" en educación, línea que será tomada por Piaget con sus etapas biológicas que descansan en la positiva idea "no te preocupes, hoy eres malo, pero mañana serás mejor". El conocimiento está en tu interior e irá saliendo en el tiempo. Pero si el conocimiento está en ti, debo dejarte libre sin coacción para que éste florezca en pleno, por lo que no puedo socializarte, ni llenarte de contenidos académicos. Si el conocimiento está en ti, no debo educarte, debo hacerte un tratamiento psicoanalítico o tal vez hipnotizarte para sacar eso oculto que ya está en ti. Los colegios no debieran tener bancos y sillas, sino divanes. 
Como vemos, lo supuesto mínimo que se pide a la educación es imposible, por lo que en su origen la idea misma de la educación, tal como se la concibe, es complejísima. Es un callejón sin salida en el que tradicionalistas y progresistas debaten de modo eterno qué es más importante y se dan mazos en la cabeza. A esto se agrega la acción socializadora de los gobiernos, lo que complejiza aún más todo.

Es por esto que en su libro Mentes educadas, el profesor Egan remira la educación como un todo y propone la llamada educación imaginativa. Se basa y toma las ideas de Lev Vigotsky, pensador ruso que elabora la llamada "teoría sociocultural" que establece que las personas conocemos distinto dependiendo de las herramientas cognitivas adquiridas que poseemos. Hay que comprender que para Vigotsky es esencial el lenguaje -pensamos y conocemos en palabras y las herramientas que nos permiten conocer tienen que ver con la sofisticación de nuestro lenguaje-. Si pensamos en palabras, nuestra capacidad de rango pensamiento se determina por la cantidad de palabras que manejemos. Si se usan más palabras, se piensa más. Si se manejan menos palabras eso determina las posibilidades de pensar. Se piensa diferente en diferentes idiomas y quienes manejan más idiomas tienen mayor capacidad de pensamiento.

Teniendo en cuenta lo anterior, muchas veces escuchamos decir que los niños son más creativos que los adultos y que son los colegios los que matan la creatividad. La verdad es que esto es un juicio errado. Los niños no imaginan más que los adultos. Nadie imagina lo que no conoce y en los adultos hay más conocimiento que en los niños. Lo que nos hace creer lo opuesto es que a los niños no les importa equivocarse, no temen al error y los adultos sí. Imaginación y conocimiento no son opuestos, de hecho son complementarios. Nadie imagina lo que no conoce y, por lo tanto, los adultos tienen mayor capacidad de imaginar que los niños, por el solo hecho de conocer más. Pueden vincular más y potencialmente debieran ser más creativos.

Teniendo en cuenta lo anterior, que es el conocimiento lo que nutre la imaginación, lo que se quiere hacer desde la educación imaginativa es, usando las emociones, poder vincular conocimiento con imaginación y abrir el camino a lo creativo. El profesor Egan elabora en este libro un relato que acompaña el devenir sociocultural de Occidente, que permite explicar los procesos de modo coherente y acabado.

Tomando la idea de Vigotsky de las herramientas socioculturales, Kieran Egan, en Mentes educadas, habla de "herramientas cognitivas", que son las herramientas que poseemos para entender el mundo. Estas tienen que ver con nuestra educación; nuestro modo de entender el mundo cambia en la medida que nos educamos. Con la educación, nuestro lenguaje se va sofisticando y, con ello, nuestro modo de comprender el mundo. Esta es la idea es la que desarrolla en este libro que tiene como subtítulo "¿Cómo las herramientas 
cognitivas dan forma a nuestro entendimiento?". En este libro se muestra como la educación hace que ganemos y perdamos elementos en el proceso educativo y propone un modo de optimizar las ganancias y minimizar las pérdidas. Propone en forma real y posible como mejorar este proceso. Del mismo modo, sugiere un nuevo modo de enseñanza basado en comprender qué es lo que emocionalmente engancha a cada uno de los tipos de entendimiento. Es decir, el profesor debe preguntarse "iquién es mi audiencia y cómo ellos conocen?" antes de planificar sus clases. Entender que las personas entienden distinto según las herramientas cognitivas que han adquirido mediante la educación, y considerar los factores que enganchan las emociones de esos entendimientos.

El autor profundiza en el tema de los distintos entendimientos. Teniendo claro que las personas no entienden igual y que esto no tiene que ver con la edad, sino con las herramientas cognitivas que la persona ha adquirido desde la educación, Kieran Egan identifica cinco tipos de entendimiento, cinco modos diferentes de entender el mundo, que no son biológicos. No se trata de la visión piagetana que plantea la idea que hoy tal vez no eres bueno, pero ya lo serás. Cada etapa para Piaget supera a la anterior y se impone. En la visión de Egan puede que nunca llegues al siguiente entendimiento y no necesariamente el nivel 1 es menos que el 2, ni menos que el 3 o que el 40 el 5. Simplemente son modos distintos y no se espera que un entendimiento (no hablemos de etapas, ya que es muy piagetano) supere al otro, sino que la idea es lograr que todos los entendimientos coexistan y colaboren.

O sea, según la visión de Egan, hay cinco modos de entender la realidad que él llama "entendimientos", y una persona adulta puede tenerlos todos, o solo algunos y ser igualmente adulto completo, solo que entiende el mundo de un modo distinto. Los cinco tipos de entendimiento poseen cada uno un kit de herramientas cognitivas que nos permiten entender de un modo distinto el mundo. Estos entendimientos según el profesor Egan son: el Entendimiento Somático (viene con el cuerpo), el Entendimiento Mítico (surge cuando el niño aprende a hablar: la oralidad), el Entendimiento Romántico (surge con la lecto-escritura, cuando el niño aprende a leer), el Entendimiento Filosófico (surge fomentado por las abstracciones y el metarrelato) y, finalmente, el Entendimiento Irónico. No todas las personas logran todos estos entendimientos y no por eso son menos personas o menos adultos. El Entendimiento Irónico implica un gran conocimiento filosófico y solo es alcanzado por un porcentaje muy mínimo de la población adulta. En el caso del Entendimiento Filosófico solo algunos niños lo alcanzan en el colegio, depende si el colegio y la familia fomentan este tipo de entendimiento, no es algo natural que venga simplemente por el hecho de crecer, ni es algo que esté en el interior de la persona. La mayoría de los adultos no son filosóficos y eso no los hace menos adultos. El colegio cumple con lograr el entendimiento mítico y romántico con seguridad. Los niños salen hablando y leyendo y escribiendo del colegio, unos con más 
propiedad que otros, sin duda. Hay muchos adultos románticos que entienden el mundo de ese modo y son felices y completos así. Lo que es fundamental es comprender que personas igualmente adultas en edad entienden el mundo de un modo distinto en relación a los tipos de entendimientos que poseen y a las herramientas cognitivas que con estos adquieren. Cada tipo de entendimiento es como si fuese una caja de herramientas que nos ayuda a comprender el mundo. Cada caja de herramientas tiene nuevas cosas que nos permite ver el mundo de un modo nuevo y diferente.

Es una mirada virtuosa que ayuda a corregir, dentro del sistema, las falencias del mismo sistema. Todos dicen "la educación es mala", "alguien tiene que hacer algo", refiriéndose a ese alguien como algo supranatural. Prima la idea que la gran reforma que arregle todo tiene que venir del Estado y se les olvida que los Estados tienen la gran tentación de manipular la educación para ponerla su servicio. Los cambios para mejorar la educación no vendrán del Estado, ya que a éste lo que más les conviene es que la educación no sea buena, ya que entonces la gente no disiente y los votos valen lo mismo. Es más fácil manipular a la gente que no sabe que a la que sabe. Así que no esperemos que el manzano de peras. Seamos nosotros mismos quienes lideremos este cambio. Son los profesores los dueños de su clase y tienen un poder muy grande en el aula. Lo primero y fundamental es que amen lo que hacen. Porque si enseñan sin amor de nada servirá. Solo el amor establece puentes. Los profesores deben amar a sus alumnos y amar lo que enseñan. Sí, el desafío de la educación imaginativa no es fácil, ya que si el alumno estudia, el profesor estudia mucho más, porque cada vez deberá dar una "vuelta de tuercas" a los contenidos para reempaquetarlos para enganchar las emociones. Si alguien piensa que es fácil, se equivoca, es desafiante y complejo, pero inmensamente entretenido. Si el profesor logra pasarlo bien aprendiendo y enseñando, entonces sus alumnos lo pasarán bien y aprenderán. La educación mejora con el hecho de que mejore el modo de enseñar de los profesores. La educación puede cambiarse por la ventana y no hay que esperar que alguien "supranatural" lo haga. Vamos por una mejor educación, cambiemos la práctica en el aula. Este libro es esencial para eso, simplemente un imperdible para todo interesado en la educación e inmensamente disfrutable para cualquier ser humano, ya que hace un análisis del proceso histórico e intelectual del ser humano en tanto a ser humano.

Magdalena Merbilháa ${ }^{1}$

Chilena. Master of Arts in Education, Kingston University. Directora Fundación Red Cultural. Associate Director IERG, Simon Fraser University, Vancouver, Canadá. E-mail: merbilhaa@ gmail.com 